\title{
EDITORIAL
}

\section{A new Editor-in-Chief for Powder Diffraction journal}

After our friend and longtime Powder Diffraction Editor-in-Chief Ting Huang passed away in 2013, I have served in an interim position while a search for a new Editor-in-Chief took place. I am pleased to announce that Dr. Camden (Cam) Hubbard has agreed to become the new Powder Diffraction journal Editor-in-Chief. Cam has served the scattering community for many years at National Institute of Standards and Technology (formerly referred to as National Bureau of Standards) and most recently at Oak Ridge National Laboratories. He has extensive knowledge of $\mathrm{X}$-ray and neutron scattering techniques, author of numerous publications, and has served as the Chairman of the
International Centre for Diffraction Data. The transition for Cam to assume Editor-in-Chief responsibilities has already begun and should be completed in September 2014.

For authors submitting manuscripts to PDJ, there will be no interruption in the submission and review process. You can continue to make inquiries to the Managing Editor, Nicole Ernst Boris (boris@icdd.com).

Congratulations to Cam, and great news for Powder Diffraction journal.

Tom Blanton Editor-in-Chief (interim) 